\title{
Economic Return on Investment of Parent Training Programmes for the Prevention of Child Externalising Behaviour Problems
}

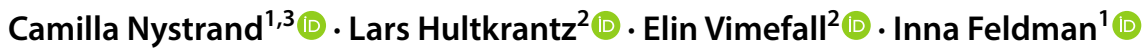

Published online: 19 October 2019

(c) The Author(s) 2019

\begin{abstract}
Economic models to inform decision-making are gaining popularity, especially for preventive interventions. However, there are few estimates of the long-term returns to parenting interventions used to prevent mental health problems in children. Using data from a randomised controlled trial evaluating five indicated parenting interventions for parents of children aged 5-12, we modeled the economic returns resulting from reduced costs in the health care and education sector, and increased long-term productivity in a Swedish setting. Analyses done on the original trial population, and on various sized local community populations indicated positive benefit-cost ratios. Even smaller local authorities would financially break-even, thus interventions were of good value-for-money. Benefit-cost analyses of such interventions may improve the basis for resource allocation within local decision-making.
\end{abstract}

Keywords Benefit-cost analysis $\cdot$ Parenting $\cdot$ Mental health

\section{Introduction}

There has been an increased use in recent years of benefit-cost analyses for evaluating early interventions for children and youth (Cunha and Heckman 2007). Both scientific literature and public reports show substantial economic returns, some with a focus on preventive interventions of mental health problems (Aos et al. 2004; Barnett and Masse 2007; Heckman et al. 2009; Reynolds et al. 2011). Within the mental health spectra, behaviour problems cause a substantial disease burden among children and adolescents, and together with an early age of onset, makes a case for early intervention (Kessler et al. 2007; Erskine et al. 2015). If effective, these could result in longer-term health and

Electronic supplementary material The online version of this article (https://doi.org/10.1007/s10488-019-00984-5) contains supplementary material, which is available to authorized users.

Camilla Nystrand

camilla.nystrand@pubcare.uu.se

1 Department of Public Health and Caring Sciences, Uppsala University, Uppsala, Sweden

2 School of Business, Örebro University, Örebro, Sweden

3 Department of Public Health and Caring Sciences, Uppsala University, BMC, Husargatan 3, 75122 Uppsala, Sweden financial gains, stemming from the fact that behaviour problems amongst children are associated with future health problems, such as antisocial behavior and an augmented risk of alcohol and drug abuse (Erskine et al. 2016; Bevilacqua et al. 2017). Further, behaviour problems have financial implications for individuals, their families and the society. For example, children with conduct problems (CP) in the United Kingdom cost on average $€ 2300$ annually to the public sector (Romeo et al. 2006), about three and a half times as much as the general population (Scott et al. 2001). If left untreated, problems may augment and lead to a diagnosis of conduct disorder, with even higher costs. Estimates from the United Kingdom show that public sector costs for children with externalising behaviours, amount to up to $€ 3650$ per child annually (Snell et al. 2013). Service use for children with coexisting problems are expected to be even higher.

From a societal perspective, child behaviour problems are also associated with an individuals' future employment and potential earnings (Knapp et al. 2011). Fletcher (2014) and Le et al. (2014) have used sibling and twin data respectively to derive results indicating that inattention/hyperactivity and aggression/rule violating behaviour is negatively associated with high school graduation and longer term job attainment. In addition, since lifetime earnings are largely affected by the completion of high school (Hultkrantz et al. 2017), the relationship between child behaviour, school achievement and 
the future financial position of these individuals becomes even more intricate.

So far, models for benefit-cost analyses for early interventions are predominantly developed in the United States and implemented for analysis at state (Aos et al. 2004) or national levels (United Kingdom) (Little and Edovald 2012), with limited evidence for other countries. Results derived from impact evaluations made in the United States, with effects sizes calibrated for an American population and with economically relevant parameters for the United States, are difficult to apply in other regions, for instance in Scandinavia. In addition, benefit-cost analyses within this field are normally based on specific trial populations or extrapolated onto the general population by estimating intervention effects from compilations of results, as through metaanalyses, giving limited evidence as to what would happen if implemented in a "real-life setting".

Within Scandinavia, attempts have been made to develop similar economic models for early intervention, for example in Denmark (The Danish National Center for Social Research (Viden til Velfard) 2018). An important driver for this work is the upsurge of interest in evaluating and estimating the socioeconomic effects of prevention and early interventions for children and young people, through the use of social investment funds set up by local governments (Hultkrantz et al. 2017). However, scientific evidence for the economic outcomes related to longer-term impacts of early interventions within the Scandinavian setting are scarce.

As an early preventive measure, parenting programs may be effective at reducing behaviour problems in children and adolescents (Thomas and Zimmer-Gembeck 2007; Litschge et al. 2010; Furlong et al. 2013). Parenting programs aim at reducing child behaviour problems through improving parenting techniques, as parents are assumed to be involved in the emergence, development and maintenance of child behaviour problems (Webster-Stratton and Hammond 1998). Parenting programs are a recommended approach for primary, secondary and tertiary prevention of behaviour problems in Sweden and are delivered in $85 \%$ of all local authorities (The National Public Health Institute of Sweden 2013). A six arm randomised controlled trial evaluated some of the most commonly used parenting programs in Sweden and found that almost all are effective at reducing behaviour problems in the short-term (Stattin et al. 2015) and maintain these reductions in the longer-term (Högström et al. 2017). In addition, economic evidence of the short-term results indicate that most are cost-effective (Sampaio et al. 2016). However, there is no evidence of the longer-term economic impact of these interventions, especially from a local level investment perspective, which we aim to explore in this study. If investing and delivering such interventions, many local authorities that have small population sizes may face difficulties in breaking-even, as benefits often accrue to other stakeholders later on. As a majority of all local authorities in Sweden are populated with less than 15,000 inhabitants and thus considered "small", a focus on their specific investment abilities and potential returns becomes relevant for local level decision-making. Although Swedish and other Scandinavian countries have relatively small population sizes, these type of analyses are applicable in other countries as well, as any decision-maker faces budget constraints and may benefit disproportionately to what has been invested. In this regard and to the authors' knowledge, no studies have been published on the return on investment of early interventions from a local authority perspective with varied population sizes, which we argue could have a substantial impact on whether or not evidence-based interventions are cost-effective. Thus, we build on the previous results of the effectiveness and short-term cost-effectiveness of the parenting programs evaluated in Sweden, by extending the analysis and forecasting the longer-term economic benefits for the trial population, as well as projecting the investment costs and potential economic returns for different local authority populations.

The aims of this paper were therefore twofolded:

(1) To forecast the longer-term economic return of four group-based parenting programs and a self-help book, compared to a waitlist control, for the prevention of behaviour problems, through the use of a decisionanalytic model.

(2) To evaluate how the rate of return was influenced by the size of a local community population.

\section{Methods}

The economic evaluation estimated the benefits and costs of five parenting interventions, in relation to a waitlist control. Estimates were derived through a state-transition modelling approach, which explored the economic effects brought about by the prevention of persistent behaviour problems, defined through instruments measuring attentiondeficit/hyperactivity problems (ADHP), CP and co-existing ADHP/CP. We monetized prevented cases by including costs related to the health care and education sector, as well as productivity losses for the children in adulthood. Data on the interventions' costs and effects were sourced from the original trial (Stattin et al. 2015), while epidemiological data to inform transitions between health states and costs related to the problem states were sourced from secondary sources, based on 2015 as a reference year. All costs and benefits 
were converted to 2015 EURO $(€)$ using price inflators (The Campbell and Cochrane Economics Methods Group). Costs and effects were discounted at $3 \%$ in the base case analysis. Outcomes are presented as benefit-cost ratios and net present values.

\section{The Interventions Evaluated}

This economic evaluation compared four group-based indicated parenting programs and a self-help book, to a waitlist control. Three of the programs, COPE (Cunningham et al. 1995), Comet (Kling and Forster, 2010) and the Incredible Years (Webster-Stratton et al. 2004), are based on social learning theory, where positive reinforcement and praise is used to improve children's emotional regulation by the use of limit setting, rules and routines. The interventions differ by the number and length of sessions, modes of delivery and outline of and components included in the sessions. Comet is the only program developed for a Swedish parent population, while the manuals of COPE and the IY have been translated from their original English versions. The fourth program, Connect (Moretti et al. 2013), is attachment-focused and intends to build empathy, reframing child behaviour and changing emotional responses by focusing on the parent-child relationship. All programs lasted between 10 and 12 weeks with weekly group sessions of between 1 and $2.5 \mathrm{~h}$. The self-help book (Forster 2009) was provided to parents to improve parenting management strategies and was created based on the program Comet. The interventions are developed for specific ages, with the IY for younger ages (3-8), Connect for 9-16 year olds and COPE, Comet and the self-help book for ages 3-12.

\section{Different Populations Evaluated}

\section{The Trial Population}

The original trial (Stattin et al. 2015) was implemented through Swedish community-based services to parents of children aged between 3 and 12 who were seeking help for their child's behaviour problems. In addition, $48 \%$ of the parents in the original trial reported that their child had an attention-deficit/hyperactivity disorder (ADHD) diagnosis at baseline (Stattin et al. 2015). We evaluated the interventions using the parent (child) population enrolled in the original trial. For this population, we estimate and report average costs and benefits per child.

\section{Local Community Populations}

In addition to the trial population, we modelled various sized local authority populations. We used national definitions (Swedish Association of Local Authorities and Regions 2017) of a small, medium and large local community in Sweden to retrieve population size estimates. Based on population sizes, we estimated the number of children between the ages 5-12 in the population (Sweden Statistics (Statistiska Centralbyrån) 2018), and through national surveys we narrowed the population to the proportion of these individuals that would be eligible (screened positive for behaviour problems) for an intervention (Folkhälsomyndigheten 2014). Further on, based on estimations from the literature (Pavuluri et al. 1996; Oh and Bayer 2015), we restricted the sample to those parents that are expected to seek help for behaviour problems in their children and would take up an intervention if offered. Final samples can be found in Fig. 1 and reported in Table 1. Results are reported for the whole population in each municipality size.

\section{Exploratory Population Based on Break-Even Point}

In addition to the local community populations, an exploratory analysis was conducted where we aimed to find out how large a local authority population would have to be in order for an investment in any of the parenting intervention to yield positive financial returns (benefit-cost ratio $\geq 1$ ). We estimate the final population based on how many would need and receive an intervention, tracing backwards from the populations found in the sample above. The final sample and its corresponding benefits and costs are reported on a group level.

\section{Data Collection from the Original Trial}

Parental report of child behaviour problems were collected at baseline, 4 months after the baseline (post-test) and at a 2 -year follow-up. The waitlist control was only allowed for 4 months due to ethical considerations, therefore the 2-year follow-up only serves as an indication of the maintenance of the interventions' effectiveness (Högström et al. 2017). Due to difficulties in finding cost data for children below the age of five with behaviour problems, we included data from children aged 5-12 and excluded children aged 3-4. No analyses were conducted to account for missing data, as attrition were deemed to have minimal bias (Stattin et al. 2015).

\section{Problem Behaviours}

Behaviour problems were estimated using two clinical instruments. Firstly, child hyperactivity and attention difficulties (ADHP) were measured using the Swanson, Nolan and Pelham scale (SNAP-IV) (Swanson 1992), a parentreporting instrument used for children aged 5-11. Although 
Fig. 1 Local community populations - breakdown of populations based on prevalence of problems and help seeking behaviour

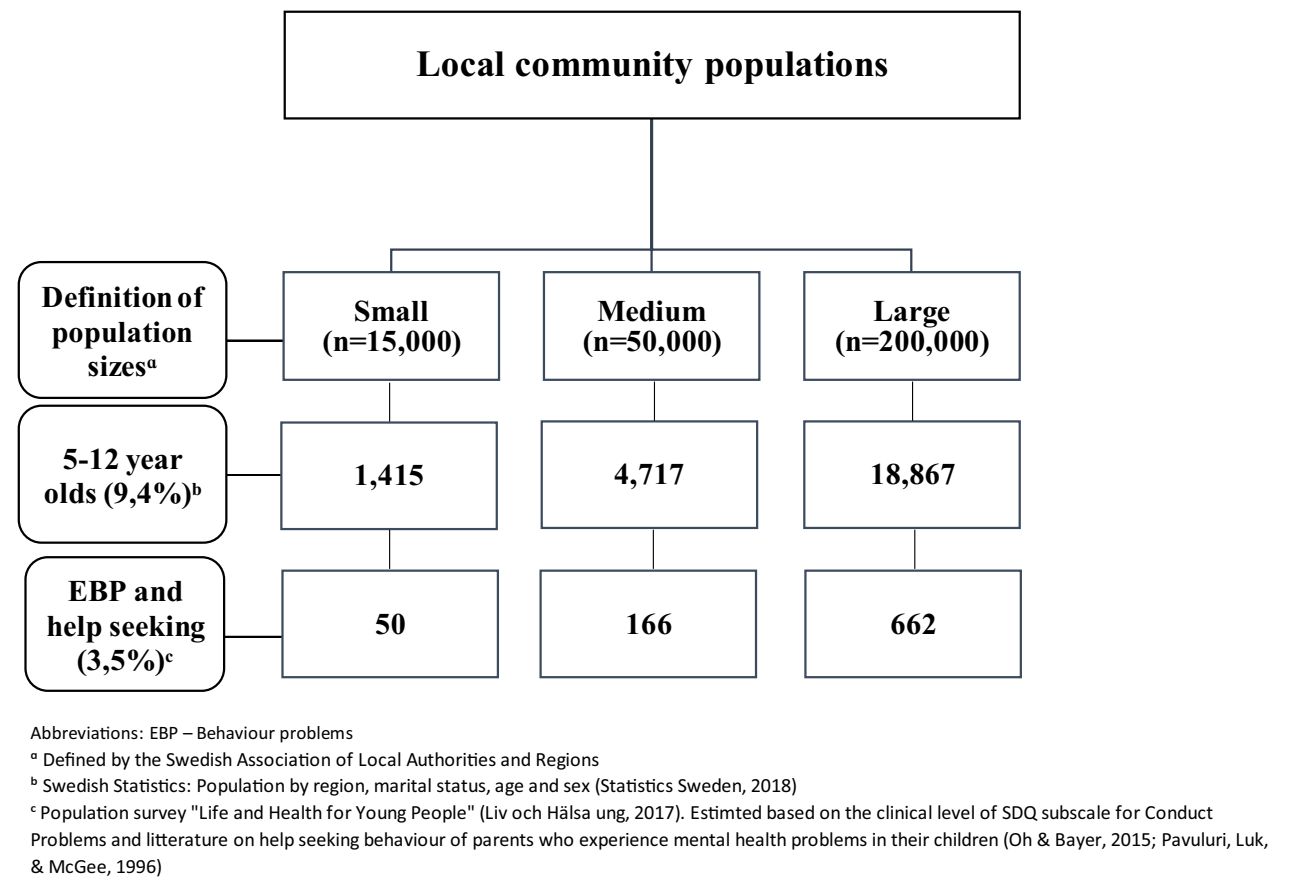

not validated for 12-year-olds, SNAP-IV was used for the full sample. Scores on two (inattention and hyperactivity/ impulsivity) of the three scales (excluding oppositional behavior) were added for a final score of "clinical levels" ADHP, fully encompassing the items for a DSM-V classification of ADHD (American Psychiatric Association 2013). Secondly, parent-reported CP were estimated with the Eyberg Child Behavior Inventory (ECBI) (Colvin et al. 1999), where we used the intensity subscale to estimate clinical levels of CP.

Although ECBI and SNAP-IV are not diagnostic instruments, they have good psychometric properties (Colvin et al. 1999; Bussing et al. 2008; Abrahamse 2015), thus we use them as a proxy for clinical levels of the problems, as has been done previously (Bonin et al. 2011; Norén Selinus et al. 2016).

\section{Intervention Costs}

The cost of delivering the various interventions were based on trial data (Stattin et al. 2015), and the short-term costeffectiveness evaluation (Sampaio et al. 2016). Costs were calculated as an average per child and based on the parents starting the different interventions. Intervention costs for implementation in various sized local authorities were estimated based on information from the trial and amended to the changed population sizes modelled. Although average treatment costs are similar in each municipality, there was a slight economies of scale for training of staff, hence costs reduced slightly with increasing population sizes. Due to implementation problems and other unexpected events in the trial, programs ran at low capacity, hence the mean cost per child for the trial population were somewhat larger than for the local community populations. Table 2 summarizes the total cost per program and mean cost per child. Due to the possibility of parents dropping out (Ozbek et al. 2018) resulting in group-sessions not running at full capacity (affecting average cost per individual), we explored the effect of increased intervention costs in a sensitivity analysis.

\section{Data from Secondary Sources}

\section{Cost for Problem Behaviours}

Short-Term Health Care and Educational Sector Costs Marginal costs related to ADHP, CP and co-existing ADHP/CP, such as additional health care sector costs, in comparison to children without problems, were included in the model and can be found in Table 3 with corresponding references in the footnotes. These costs were estimated by calculating an average cost derived from European costing studies based on their potential similarity to the Swedish welfare system. Inclusion and exclusion criteria, search results, included studies and costing-analyses can be found in the technical report (Nystrand 2018). It should be noted that we could only find a small number of studies estimating incremental costs. We try to account for this uncertainty by using probabilistic sensitivity analyses, described further below. In addition to health care costs, we included educational sector costs containing data on educational support in the form of assistants, smaller group sessions and special pedagogical support etc. Costs for children in special needs schools were excluded from the analyses as they often have more severe 
Table 1 Input parameters and uncertainty ranges used in the decision-analytic model

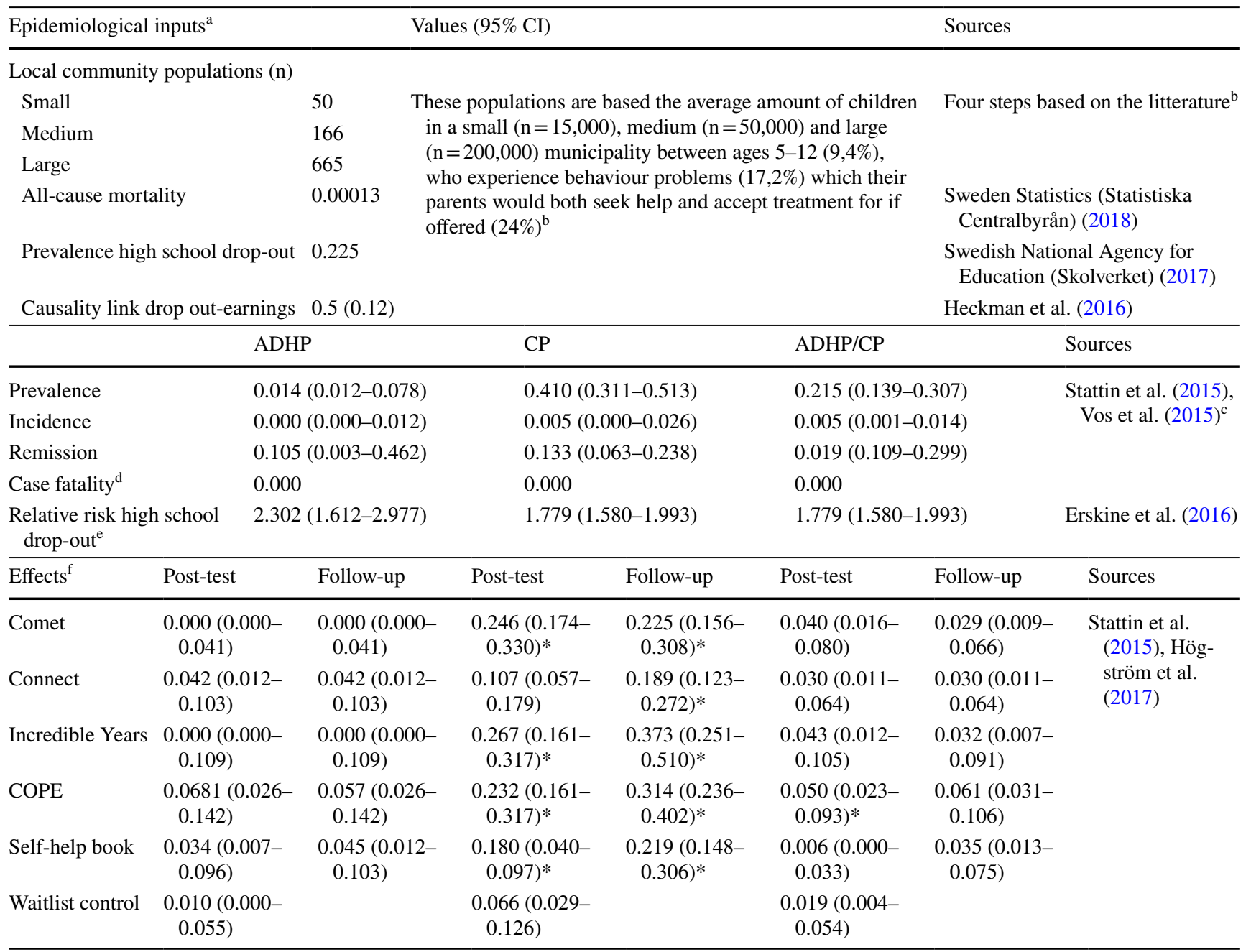

To include parameter uncertainty in the model, each epidemiological parameter (incidence, prevalence and remission) as well as the effectiveness measures and the causality link between drop-out and earnings, was attributed a beta distribution in the probabilistic analysis. Epidemiological data and effects are presented as probabilities

$P S A$ probability and sensitivity analysis, $G B D$ global burden of disease, $A D H P$ attention-deficit/hyperactivity problems, $C P$ conduct problems, CI confidence interval

*Significant compared with the waitlist control at a significance level of $<0.05$

${ }^{a}$ All epidemiological inputs (except for population) in the table are averages between ages 5 and 20. In the decision analytic model, specific age rates were used

${ }^{b}$ Population sizes of small, medium and large communities are all based on (1) how many parents are treatment seeking and would take up an intervention, if offered, for behaviour problems in their children (Oh and Bayer 2015; Pavuluri et al. 1996), (2) out of the amount of children between the ages 5 and 18 (Statistics Sweden 2018) within the normal population who are estimated to have behaviour problems (Folkhälsomyndigheten. 2014), (3) for three different population sizes (Swedish Association of Local Authorities and Regions 2017)

${ }^{\mathrm{c}}$ The figures from the GBD (2015) were collected from the following website: http://ghdx.healthdata.org/gbd-results-tool

${ }^{\mathrm{d}}$ As per the 2015 GBD study, case fatality was zero and no estimate of excess mortality due to ADHP and CP was found in the literature

${ }^{\mathrm{e}} \mathrm{We}$ used a lognormal distribution for the relative risk of high school drop-out

${ }^{f}$ Effects are expressed as proportion reduction of the outcome. It is based on the post-test and 2-year follow up. Because of the lack of a control group after post-test, the results from the waitlist control at 4 months are used for the 2 year follow-up (assuming a constant linear reduction of the outcome)

and comorbid diagnoses which require more assistance. Only public sector costs were accounted for. Costs accruing to other sectors were excluded due to lack of relevant data.
The costs ranged between $€ 321$ and $€ 1888$ annually for $\mathrm{CP}$ and ADHP respectively. 
Table 2 Intervention cost (2015 EUR€) for the trial population and for a small, medium and large municipality population

\begin{tabular}{|c|c|c|c|c|c|}
\hline Cost categories & Comet & Connect & Incredible years & COPE & Self-help book \\
\hline Number of children small population & 50 & 50 & 50 & 50 & 50 \\
\hline Number of children medium population & 166 & 166 & 166 & 166 & 166 \\
\hline Number of children large population & 665 & 665 & 665 & 665 & 665 \\
\hline \multicolumn{6}{|l|}{ Training costs per practitioner } \\
\hline Training course fee & 1975 & 1122 & 494 & 628 & - \\
\hline Number of training days & 8 & 3 & 3 & 3 & - \\
\hline Average salary per training day & 127 & 127 & 127 & 127 & - \\
\hline \multicolumn{6}{|l|}{ Travel cost for training } \\
\hline Average hotel cost & 411 & 124 & 108 & 26 & - \\
\hline Average trip cost & 58 & 62 & 54 & 12 & - \\
\hline Average travel allowance per day & 12 & 13 & 12 & 3 & - \\
\hline Total travel cost $\mathrm{t}^{\mathrm{b}}$ & 567 & 226 & 195 & 48 & - \\
\hline Average total training cost/practitioner & 3555 & 2360 & 1701 & 1688 & - \\
\hline \multicolumn{6}{|l|}{ Running costs } \\
\hline Time per session (h) & 3 & 2 & 3 & 3 & - \\
\hline Set of sessions/program & 11 & 10 & 12 & 10 & - \\
\hline Number of participants/program & 10 & 12 & 10 & 25 & - \\
\hline Number of practitioners/program & 2 & 2 & 2 & 2 & - \\
\hline Max number of programs run per year/practitioner ${ }^{c}$ & 4 & 4 & 4 & 4 & - \\
\hline Number of hours per practitioner preparing and running sessions & 61 & 30 & 66 & 55 & - \\
\hline Cost per practitioner preparing and running sessions ${ }^{\mathrm{d}}$ & 1013 & 503 & 1106 & 921 & - \\
\hline Rent of the venue ${ }^{\mathrm{e}}$ & 675 & 335 & 737 & 614 & - \\
\hline Cost of materials (curriculum + student material) & - & - & - & - & 14 \\
\hline Yearly license fee & 12,498 & - & - & - & - \\
\hline Subtotal running cost for one program & 5826 & 1340 & 2948 & 2456 & 14 \\
\hline Average intervention cost per child for the trial population ${ }^{\mathrm{a}}$ & 931 & 334 & 1302 & 478 & 14 \\
\hline Total intervention cost small pop & 46,412 & 97,66 & 23,134 & 7793 & 818 \\
\hline Total intervention cost medium pop & 154,707 & 32,552 & 77,113 & 25,978 & 2726 \\
\hline Total intervention cost large pop & 618,830 & 130,210 & 308,451 & 103,911 & 10,904 \\
\hline
\end{tabular}

All information is based on project documentation attained from a randomized controlled trial including the same interventions. Further information can be obtained in previously published studies (Stattin et al. 2015; Sampaio et al. 2016). Totals may not exactly reflect the sum of the variables included, as each variable is rounded off to the closest integer

${ }^{\text {a }}$ The costs for the trial population is solely based on information from the RCT that this study is based on and can be found in detail in Sampaio et al. 2016. The costs for the other populations are based on the RCT, but amended to fit larger populations. Further information on the exact amendments made can be found in the technical report (Nystrand 2018)

${ }^{\mathrm{b}}$ Total travel cost include cost for transport and accommodation (reported above as a one time cost) and travel allowance times the number of training days

${ }^{\mathrm{c}} \mathrm{We}$ assume that each practitioner has the capacity to run four consecutive programs annually

${ }^{\mathrm{d}} \mathrm{We}$ assume that the practitioners need as much time for preparation as running the sessions

${ }^{\mathrm{e}}$ Hourly rate for renting a venue within the municipal sector

Productivity Based on Lifetime Earnings Between Ages 20 and 65 To value the effect of the interventions on productivity, we used estimates of lifetime earnings based on different education levels (Hultkrantz et al. 2017). These estimates were based on data from a national register containing yearly information on individual level earnings from income and self-employment for all Swedish residents aged 16-65. Earnings were divided between individuals who graduated from upper secondary school (max 20 years of age), and for those who only graduated from compulsory education (9 years of education). By calculating the difference between these and subtracting the cost of secondary school education, they estimated the expected difference in earnings between these two types of individuals, which amounted to 1.6 million SEK ( $€ 163,000$ ). This estimate was derived from assuming that the amount of variation in earnings that could be attributed to educational achievement was $50 \%$, This "causality factor" was derived from Swed- 
Table 3 Cost for behavior problems (2015 EUR€) used in the decision-analytic model

\begin{tabular}{|c|c|c|c|}
\hline Yearly cost-offsets & Mean (uncertainty range) & Distribution used in PSA & Source \\
\hline \multicolumn{4}{|l|}{ ADHP } \\
\hline Health care & 1888 (699-3076) & Gamma & Average estimation $^{\mathrm{a}}$ \\
\hline \multicolumn{4}{|l|}{ Conduct problems (CP) } \\
\hline Education & 849 (Range $\pm 20 \%$ ) & Triangular & Average estimation ${ }^{b}$ \\
\hline Health care & 321 (Range $\pm 20 \%$ ) & Triangular & \\
\hline \multicolumn{4}{|l|}{ Coexisting ADHP/CP ${ }^{f}$} \\
\hline Health care & 321 (Range $\pm 20 \%)$ & Triangular & Average estimation $^{c}$ \\
\hline \multicolumn{4}{|l|}{ High school drop out } \\
\hline $\begin{array}{l}\text { Education (one time } \\
\text { cost) }\end{array}$ & $29,006($ Range $\pm 20 \%)$ & Triangular & \\
\hline $\begin{array}{l}\text { Marginal labour mar- } \\
\text { ket earnings (one } \\
\text { time cost) }\end{array}$ & 142,288 & No uncertainaty modelled & LISA database $^{\mathrm{d}}$ \\
\hline
\end{tabular}

Costs are presented in 2015 EUR€

$A D H P$ attention-deficit/hyperactivity problems, $C P$ conduct problems, $P S A$ probabilistic sensitivity analysis

${ }^{a}$ Hakkaart-van Roijen et al. (2007), Thernlund and Schacht (2010), Braun et al. (2013), Holden et al. (2013), Snell et al. (2013), Telford et al. (2013), Klora et al.(2015)

${ }^{\mathrm{b}} \mathrm{S}$ cott et al. (2001), O’Neill et al. (2013)

${ }^{\mathrm{c}}$ Scott et al. (2001, O’Neill et al. (2013)

${ }^{\mathrm{d}}$ Statistics Sweden (SCB) (2016)

${ }^{\mathrm{e}}$ Estimated up until 65 years of age (Hultkrantz et al. (2017)

${ }^{\mathrm{f}}$ Due to the lack of cost data for the coexisting state ADHP/CP, it was conservatively assumed that the resource use by the these individuals mirrored the lowest cost estimated for either ADHP or CP ish literature (Björklund et al. 2010), but we use parameter uncertainty from an American study (Heckman et al. 2016) in our probabilistic model. However, no uncertainty was included in the model for individual level earnings, as the estimates were based on national register data almost fully representing the whole population.

\section{Epidemiology to Estimate Transition Probabilities}

Age-specific incidence and prevalence data used to populate the model and estimate transition probabilities between health states, were collected from the Global Burden of Disease study (Global Burden of Disease 2016; Disease and Injury Incidence and Prevalence Collaborators*2017). Average estimations on remission were analysed based on data from the literature (Nystrand 2018). Estimates for the health state ADHP/CP were obtained based on a meta-analysis of the co-existence between the two problems, explained further in the technical report (Nystrand 2018).

\section{Analyses}

\section{Effectiveness of Interventions}

Clinically Significant Reliable Change Index (CS/RCI) To estimate the interventions' effectiveness in relation to the waitlist control, the CS/RCI (Jacobson and Truax 1991) method was used for both ECBI and SNAP-IV. CS/RCI combines the clinical significance (CS) and the reliability of the change (RCI). This method was employed in the shortterm cost-effectiveness evaluation of the trial and explained more thoroughly there (Sampaio et al. 2016).

The effects of the interventions were estimated as the proportion of "recovered" cases for both post-test and the 2-year follow-up, reported in Table 1. Recovered cases were defined as a clinical significant and reliable change from above the pre-determined clinical cut-off to below for each scale. As the post-test data was collected at 4 months post baseline, we extrapolated the data into yearly proportions. Also, since the waitlist control was dropped following the post-test measurement, the proportion of "recovered" cases in the waitlist at the 2-year follow-up was assumed to be the same amount as at post-test, indicating a linear natural remission trend. We used this assumption to be able to estimate the interventions' effect at 2 years. Epidemiological studies have found annual probabilities of natural remission from conduct disorder and ADHD between 7 and 29\% (Kim-cohen et al. 2005; Lahey et al. 2005) and 4-21\% (Mannuzza et al. 1998; Biederman et al. 2006b) respectively. We estimated annual remission probabilities between $11 \%$ for attention difficulties and $14 \%$ for conduct problems, based on transitions made by individuals 
in the waitlist control group between baseline and post-test (Nystrand 2018). We thus apply these to the waitlist at twoyears and believe that it fairly resembles the probability of natural remission.

\section{Epidemiology}

Transition probabilities to move individuals between the health states were based on (1) data from the waitlist control group estimated between baseline and post-test using SNAP-IV and ECBI and (2) amendment of the trial data to fit the epidemiological trend based on Swedish population level data (Erskine et al. 2014; Sweden Statistics 2018). These probabilities corresponded to; incidence, remission, case fatality and all-cause mortality. We explain how these two data types were merged in the technical report (Nystrand 2018). Using only trial data for the epidemiological inputs would assume that the epidemiology remains constant over the full modelling period to reflect trial data availability (measured at baseline and post-test). In addition, to solely use population level data would have underestimated the prevalence of the behaviour problems in the populations receiving the interventions (as they are targeted). Epidemiological data from the trial were determined using the same method as for calculating the intervention effects, the CS/RCI method (Jacobson and Truax 1991).

\section{State-Transition Model}

A probabilistic decision-analytic model was developed to calculate benefit-cost ratios of the five interventions in relation to a waitlist control, for the prevention of persistent behaviour problems. To simulate the problem pathways for the intervention and comparator scenarios, we developed a multiple cohort Markov model with yearly transitions between health states. Microsoft Excel 2016 was used to model five different health states-well, "problems" (ADHP, $\mathrm{CP}$ or co-existing ADHP/CP) and a dead state. The dead state acts as an absorbing (and natural) state to account for all-cause mortality (Kattan 2009). We assumed each state to be mutually exclusive. At the starting cycle (year zero), the problem states included the prevalent cases of ADHP, CP and ADHP/CP, estimated as the proportion of children at baseline (from the trial) who scored above the clinical cutoffs on ECBI and/or SNAP-IV, while the remaining population were in the well state. A conceptual diagram of the model is presented in Fig. 2. The effects of the interventions were applied in the first and second cycle of the model to the prevalence of the problems. We assumed that the potential reduction in persistence of the problems move individuals back to the well state where they incurred no extra costs, although a reduction in costs would most likely happen over a longer time period. We modelled the transitions on an annual basis for each age-cohort, where different agecohorts were modelled for different interventions. Comet, COPE and the self-help book were modelled for 5-12 year olds, the Incredible Years for 5-8 year olds and Connect for 9-12 year olds. The populations were modelled over a time horizon lasting until the children were 20 years of age.

\section{Beyond the Age of 20}

At age 20, the prevalent cases in each of the three problem states (excluding the well and dead state) were estimated. The potential impact fraction (PIF) method (Morgenstern and Bursic 1982) was used to estimate how a change in prevalence of the three problems for each intervention arm affected the prevalence of high school drop-out, based on relative risk estimates (Erskine et al. 2016). Hence, if an intervention, compared to the waitlist control, generated fewer prevalent cases of ADHP, CP and/or ADHP/CP, it would reduce the number of individuals dropping out of high school, since the relative risk of high school drop-out conditional on any of the problems is greater than one.

The PIF is computed in the following way:

$$
P I F=\frac{\left(p-p^{1}\right)+\left(R R *\left(p-p^{1}\right)\right)}{\left(1-p^{1}\right)+\left(R R * p^{1}\right)}
$$

where $\mathrm{p}$ is the prevalence of the risk factor (ADHP, CP, $\mathrm{ADHP} / \mathrm{CP}$ ) at the end of the modeling period for the intervention scenarios, $\mathrm{p}^{1}$ is the prevalence of the risk factor in the waitlist control and RR is the relative risk of high school drop-out conditional on having any of the risk factors respectively. The resulting PIF was multiplied by the number of people in each intervention arm that would drop-out of high school without the intervention in place (n times the population drop-out prevalence (Swedish National Agency for Education 2017)). The result provided an estimate of the change in number of dropouts as a result of each intervention. We assumed that dropping out of high school was the inverse of receiving a high school diploma by age 20. PIF was used to estimate the interventions' effect on productivity, estimated based on the receipt of a high school diploma at the age of 20 .

\section{Probabilistic Modelling and Sensitivity Analyses}

The uncertainty around the parameters in the model was dealt with using probabilistic sensitivity analyses (Briggs et al. 2012). We used Microsoft Excel 2016 to run Monte Carlo simulations with 5000 iterations which produced confidence intervals (CI) of $95 \%$ around the health outcomes, net costs and net return on investment. We assigned distributions to each parameter depending on the type of 


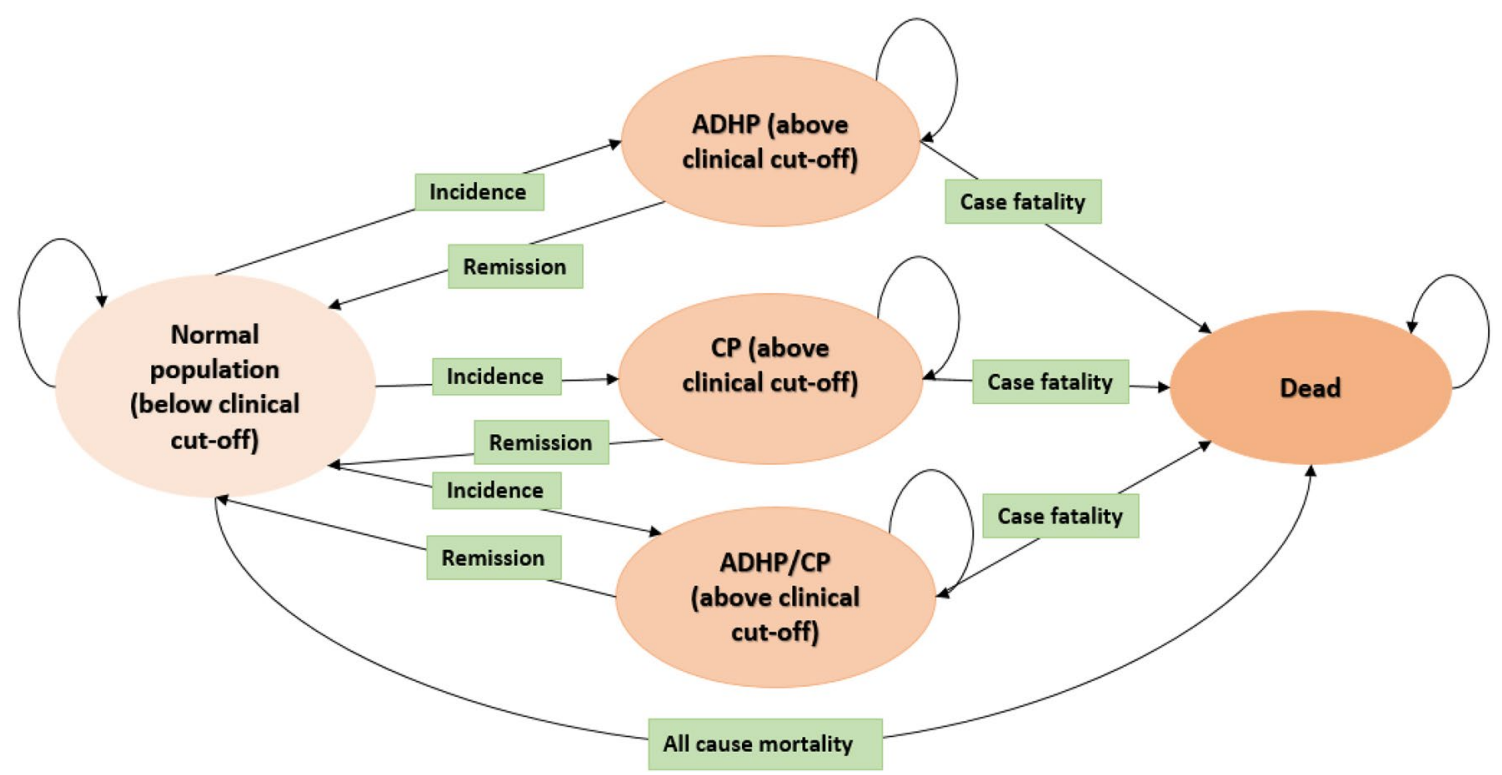

Fig. 2 Conceptual model of the state-transitioning model used to estimate the benefit-cost of the interventions. $A D H P$ attention-deficit/hyperactivity problems, $C P$ conduct problems

data. Beta distributions were assigned to all probabilities due to it being constrained between values of zero to one, while gamma distributions ranging between zero and positive infinity were used for the costs due to the skewness of the data. For some cost data, we were only able to retrieve average estimates without information regarding its spread. In these cases, we used a triangular distribution, with a range of $\pm 20 \%$, to incorporate some kind of uncertainty around the averages. We used the lognormal distribution for the relative risks as these estimates consist of ratios, whereby the natural $\log$ is used to estimate the variance around the mean. These parameters are shown in Table 1.

Univariate sensitivity analyses for certain parameters were conducted to estimate the impact of potential changes of the parameters, deemed relevant for decision-makers.

First (1), we looked at only using post-test effects as the follow-up measure was lacking a control group. Second (2), we added "recovered" and "improved" cases together to form the effectiveness measure, effectively using the traditional "cases" and "non-cases" as an outcome. Third (3), we doubled intervention costs as these may vary greatly between local authorities and to provide a more conservative costing approach. We also modelled what would happen with (4) a smaller, $0 \%$, and (5) a larger, $6 \%$, discount rate on both costs and effects. In the last two analyses, we used (6) only educational sector cost-offsets, as these are borne by the same authority (the municipality) that would financially be responsible for implementing the parenting interventions, and (7) only educational and health care sector costs, disregarding the interventions' effect on labour market earnings.

\section{Results}

\section{Estimated Benefit-Cost Ratios for the Trial Population}

Table 4 shows the base case results of all the modelled populations, with respect to each intervention in comparison to the waitlist control. The results vary depending on the size of the population.

\section{The Trial Population}

The intervention costs ranged between $€ 13$ (95\% CI $€$ 13- $€$ 13) per individual for the self-help book to $€ 1142$ (95\% CI $€ 1136-€ 1148$ ) for the Incredible Years program. We found that all interventions yielded positive incremental cost-offsets in comparison to the waitlist control. In addition, all interventions had positive net present values and benefit-cost ratios ranging between 5.96 (the Incredible Years) to over 300 (self-help book) per invested Euro.

\section{The Community Populations}

When simulating what the results would look like if the interventions were implemented in various sized local communities, we found similar positive results as for the trial population, which remained so throughout the analyses. Starting from a small $(15,000)$, medium $(50,000)$ and large $(200,000)$ population, the amount of children who (1) were between the ages 5-12, (2) would screen positive of behaviour problems and (3) would have parents who were 
Table 4 Results (EUR€) of the base case cost, cost-offsets and cost-benefit generated by four parenting programs and a self-help book, in comparison to a waitlist control, for various population sizes

\begin{tabular}{|c|c|c|c|c|}
\hline & $\begin{array}{l}\text { Intervention costs } \\
\text { Mean }(95 \% \mathrm{CI})\end{array}$ & $\begin{array}{l}\text { Incremental cost offsets } \\
\text { Mean }(95 \% \mathrm{CI})\end{array}$ & $\begin{array}{l}\text { Benefit-cost ratio } \\
\text { Mean }(95 \% \mathrm{CI})\end{array}$ & $\begin{array}{l}\text { Net present value } \\
\text { Mean }(95 \% \mathrm{CI})\end{array}$ \\
\hline \multicolumn{5}{|l|}{ Trial population } \\
\hline Comet $(n=176)$ & $817(813-821)$ & $5682(5551-5814)$ & $7.00(6.84-7.17)$ & 4865 (4733-4997) \\
\hline Connect $(n=215)$ & $295(293-296)$ & $3106(3013-3199)$ & $10.61(10.29-10.93)$ & $2811(2718-2904)$ \\
\hline Incredible Years $(n=104)$ & $1142(1136-1148)$ & $6741(6576-6905)$ & $5.96(5.81-6.11)$ & $5598(5434-5763)$ \\
\hline $\operatorname{COPE}(n=161)$ & 417 (415-419) & $6563(6426-6700)$ & $15.80(15.46-16.13)$ & $6146(6009-6283)$ \\
\hline Self-help book $(n=162)$ & $13(13-13)$ & $4120(4023-4217)$ & $328.04(320.09-335.99)$ & 4107 (4010-4204) \\
\hline \multicolumn{5}{|l|}{ Small population $(\mathrm{n}=50)$} \\
\hline Comet & $42,819(42,614-43,023)$ & $270,299(263,985-276614)$ & $6.31(6.19-6.43)$ & $227,481(221,156-233,805)$ \\
\hline Connect & $10,383(10,331-10,435)$ & $150,307(145,885-154,728)$ & $14.48(14.12-14.83)$ & $139,924(135,501-144,347)$ \\
\hline Incredible Years & $25,694(25,573-25,816)$ & $327,997(320,850-335,143)$ & $12.77(12.5-12.98)$ & $302,302(295,159-309,446)$ \\
\hline COPE & $8541(8498-8585)$ & $332,854(326,219-339489)$ & $38.97(38.39-39.55)$ & $324,313(317,676-330,950)$ \\
\hline Self-help book & $611(608-614)$ & $207,844(203,164-212,524)$ & $340.10(334.05-346.10)$ & $207,233(202,553-211,913)$ \\
\hline \multicolumn{5}{|l|}{ Medium population $(\mathrm{n}=166)$} \\
\hline Comet & $142,961(142,296-143626)$ & $918,645(887,534-929$ 997) & $6.46(6.24-6.48)$ & $764,806(743,542-786,070)$ \\
\hline Connect & $34,514(34,345-34,683)$ & $511,945(490,476-520,207)$ & $14.95(14.28-15.00)$ & $470,434(455,564-485,303)$ \\
\hline Incredible Years & $84,865(84,469-85,260)$ & $\begin{array}{l}1,152,373(1,078,720- \\
1,126,774)\end{array}$ & $13.66(12.77-13.22)$ & $\begin{array}{l}1,016,362(992,344- \\
1,040,379)\end{array}$ \\
\hline COPE & $28,729(28,592-28,867)$ & $\begin{array}{l}1,060,968(1,096,769- \\
1,141,386)\end{array}$ & $37.15(38.36-39.54)$ & $\begin{array}{l}1,090,362(1,068,049- \\
1,112,675)\end{array}$ \\
\hline Self-help book & 2034(2024-2044) & $697,078(683,052-714,521)$ & $345.20(337.51-349.60)$ & $696,732(680,997-712,466)$ \\
\hline \multicolumn{5}{|l|}{ Large population $(n=662)$} \\
\hline Comet & $570,650(567,881-573,420)$ & $\begin{array}{l}3,709,564(3,545,585- \\
\quad 3,715,218)\end{array}$ & $6.54(6.24-6.48)$ & $\begin{array}{l}3,055,302(2,970,357- \\
3,140,247)\end{array}$ \\
\hline Connect & $138,502(137,817-139,187)$ & $\begin{array}{l}2,074,936(1,959,388- \\
2,078,162)\end{array}$ & $15.09(14.22-14.93)$ & $\begin{array}{l}1,879,323(1,819,920- \\
1,938,725)\end{array}$ \\
\hline Incredible Years & $341,767(340,165-343,369)$ & $\begin{array}{l}4,635,020(4,309,349- \\
4,501,317)\end{array}$ & $13.62(12.67-13.11)$ & $\begin{array}{l}4,060,234(3964286- \\
4,156,182)\end{array}$ \\
\hline COPE & $114,863(114,288-115,438)$ & $\begin{array}{l}4,381,965(4,381,453- \\
\quad 4,559,692)\end{array}$ & $38.46(38.34-39.50)$ & $\begin{array}{l}4,355,856(4,266,717- \\
\quad 4,444,995)\end{array}$ \\
\hline Self-help book & $8119(8081-8158)$ & $\begin{array}{l}2,777,912(2,728,704- \\
2,854,419)\end{array}$ & $344.43(337.68-349.91)$ & $\begin{array}{l}2,783,354(2,720,498- \\
2,846,210)\end{array}$ \\
\hline
\end{tabular}

All estimates are discounted with a 3\% annual rate. Net present value is calculated as incremental cost offsets minus intervention costs

Results for in 2015 EUR€. For the trial population, the results are presented per individual, while for the small, medium and large population, results are presented for the whole municipality population that would receive the intervention, indicated in each paragraph

CI Confidence interval

help-seeking boiled down to 50 (small), 166 (medium) and 662 (large). In text, we present results from the small population $(\mathrm{n}=50)$ since this is the most common sized municipality in Sweden. The intervention costs were estimated between $€ 611$ (95\% CI $€ 608-€ 614$ ) for the least costly option (the self-help book) to $€ 42,819$ (95\% CI $€$ $42,614-€ 43,023)$ for Comet. COPE generated the largest incremental cost-offsets with a total of $€ 332,854$ (95\% CI $€ 326,219-€ 339,489)$. When analysing the costs and forecasted cost-offsets in relation to each other, we found that the benefit-cost ratios were larger than unity for all interventions, indicating positive returns on investment, with the self-help book showing the most substantial returns. Net present values ranged between $€ 139,924$ (95\% CI $€$
135,501-€ 144,347) for Connect to $€ 324,313$ (95\% CI $€$ $317,676-€ 330,950)$ for COPE.

\section{The Break-Even Analysis}

The results from the exploratory break-even analysis can be found in Table 5. The earliest point of break-even occurred for all interventions except Comet at a population of 257 inhabitants. Hence, only one parent in our target group would have to receive the intervention for it to generate cost-offsets larger than the investment cost; a positive net present value. In summary, a municipality would have to invest between $€ 12$ (the self-help book) to $€ 10,051$ (for Comet) for the intervention to break-even. 
Table 5 Results (EUR€) of the base case break-even analysis of four parenting programs and a self-help book, in comparison to a waitlist control, for a hypothetical population

\begin{tabular}{|c|c|c|c|c|c|c|}
\hline \multicolumn{2}{|l|}{ Intervention costs } & $\begin{array}{l}\text { Incremental cost } \\
\text { offsets }\end{array}$ & BCR & Net present value & $\begin{array}{l}\text { No. needed per } \\
\text { intervention for } \\
\text { BCR } \geq 1^{\text {a }}\end{array}$ & $\begin{array}{l}\text { No. needed in } \\
\text { population for } \\
\text { BCR } \geq 1^{b}\end{array}$ \\
\hline \multicolumn{2}{|l|}{ Mean (CI) } & Mean $(\mathrm{CI})$ & Mean $(\mathrm{CI})$ & Mean (CI) & Value & Value \\
\hline \multicolumn{7}{|c|}{ Hypothetical population } \\
\hline Comet & $\begin{array}{l}10,051(10,004- \\
10,099)\end{array}$ & $\begin{array}{l}10,935(10,683- \\
11,187)\end{array}$ & $1.10(1.07-1.12)$ & $884(625$ to 1143$)$ & 2 & 514 \\
\hline Connect & $3166(3150-3182)$ & $3139(3046-3232)$ & $1.00(0.97-1.03)$ & $-27(-123$ to 69$)$ & 1 & 257 \\
\hline Incredible Years & $5592(5566-5618)$ & 6709 (6554-6863) & $1.21(1.18-1.23)$ & 1117 (961 to 1273$)$ & 1 & 257 \\
\hline COPE & $4745(4721-4768)$ & $6479(6343-6616)$ & $1.38(1.35-1.41)$ & $\begin{array}{l}1735(1596 \text { to } \\
1873)\end{array}$ & 1 & 257 \\
\hline Self-help book & $12(12-12)$ & $4209(4111-4307)$ & $\begin{array}{l}345.88(337.58- \\
354.18)\end{array}$ & $\begin{array}{l}4197(4099 \text { to } \\
4295)\end{array}$ & 1 & 257 \\
\hline
\end{tabular}

Results are presented in 2015 EUR€ per the "number needed per intervention for BCR $\geq 1$ "

$B C R$ benefit-cost ratio, $C I$ Confidence interval

a(1) how many parents are treatment seeking and would take up an intervention, if offered, for behaviour problems in their children (Oh and Bayer 2015; Pavuluri et al. 1996), (2) out of the amount of children between the ages 5-18 (Statistics Sweden 2018) within the normal population who are estimated to have behaviour problems (Folkhälsomyndigheten 2014) which would generate a benefit-cost ratio of or above unity $(\geq 1)$

${ }^{b}$ Number of people in the whole hypothetical municipal population, based on how many children between the ages $5-18$ there are in the average population (Statistics Sweden 2018)

\section{Sensitivity Analyses}

Results from the sensitivity analyses for the trial and local community populations can be found in the Electronic Supplementary Appendix. For almost all analyses, the net return on investment increased with population size, in comparison to the base-case analysis where benefit-cost ratios did not alter much between populations. Only two of the analyses (excluding costs outside of the local authority setting and excluding cost-offsets due to high school drop-out) resulted in negative returns, while the other analyses indicated that the initial results remained robust to parameter changes. When including only the local authority sector costs, only the selfhelp book yielded positive BCRs throughout the populations analysed (38.11 (95\% CI 37.57-38.66) and 39.02 (95\% CI 38.46-39.59) respectively for the trial and small population). Only for the large population did the Incredible Years and COPE yield positive returns as well. Similar results are found when excluding costs related to high school drop-out (excluding lifetime labour market earnings).

\section{Discussion}

In the present study, a decision-analytic model was used to forecast the longer-term economic impact of four parenting programs, along with a self-help book, in comparison to a waitlist control. We conducted three types of analyses; one on a trial population, one on hypothetical local community populations and a third analysis using an exploratory breakeven approach to find the minimum population size required to generate positive returns on investment.

The results indicate benefit-cost ratios above unity for all interventions throughout the modelled populations, with estimates between 5.96 and 15.80 per Euro invested for the four parenting programs and substantially larger benefit-cost ratio for the self-help book. COPE generated the largest net present values. The break-even analysis showed that all interventions yielded positive returns on investment if willing to invest up to $€ 10,051$. The results therefore indicate that all interventions are of good value-for-money, even for small authorities, and yields high positive returns on investment.

\section{Discussion of Results}

In line with the effectiveness evaluation, the effects are larger for reducing cases of CP rather than ADHP, which likely stems from the fact that a majority of the programs were developed to target child CP. Looking at the economic evidence, the results vary somewhat between the trial and local community populations. Due to implementation problems, some of the delivered programs within the trial did not run at the optimal capacity, hence the costs per child were higher. This had a substantial impact on the intervention costs for the Incredible Years program in the trial. However, this only had an effect on the magnitude of the benefit-cost ratios, rather than the direction due to the substantial cost-offsets 
related to a reduction of behaviour problems. The largest benefit-cost ratios were generated by the self-help book. Due to its low implementation (only material) costs and with a relatively large impact on all health outcomes, it generated substantial returns on investment even with low population sizes.

\section{Comparison to Other Studies in the Field}

In general, the results from this study are in line with the economic evidence found in the literature as well as in nonscientific reports, suggesting positive returns on investment and high probabilities of cost-effectiveness. Bonin et al. (2011), Sampaio et al. (2018) and Mihalopoulos et al. (2007) applied population-based models within Australia and the UK to estimate whether parenting interventions were cost-effective and cost-saving over the longer term. Bonin et al. (2011) used a generic parenting intervention based on effectiveness estimates from the literature and by simulating an intervention using various effectiveness scenarios, they found that it yielded approximately $€ 7300$ in net-savings (NPV) to the public during 25 years following delivery of a group-based intervention. Seen from the small population, our data suggest net-savings between $€ 2798$ and $€ 6486$. This difference is likely to be due to fewer public sectors included in our analysis. Sampaio et al. (2018) and Mihalopoulos et al. (2007) modelled children up until the age of 18 , whose parents had received the parenting program Triple $\mathrm{P}$ (Sanders 1999) at various intensity levels in an Australian setting. They found that Triple P was both cost-effective at the local willingness-to-pay threshold and cost-saving if the intervention would reduce the level of conduct disorder by at least $7 \%$.

O'Neill et al. (2013) conducted a cost-effectiveness analysis and a longer term benefit-cost approximation of the Incredible Years program in Ireland. Their benefit-cost analysis included costs related to education, crime and unemployment. Their forecast resulted in a net present value of $€$ 3445 per child, which compares to our results of the Incredible Years program of $€ 6046$ per individual, delivered in a small population.

Although self-help parenting interventions, such as bibliotherapy, have been deemed effective in the literature (O'Brien and Daley 2011), no economic evaluations other than the short-term cost-effectiveness evaluation of the current trial, have been conducted. As the effectiveness results of this trial are in line with previous research and self-help options generally require fewer hours by practitioners, the results are expected and the magnitude of the returns unsurprising.

Similar evidence can be found outside of the published literature where comparable economic models have been used to evaluate preventive interventions (Aos et al. 2004).
State level estimates from the US reported a benefit-cost ratio for behavioural parent training programs of 20.63 including benefits from changes to both primary and secondary participants (e.g., parents) (Washington State Institute for Public Policy 2018). The estimated benefits from changes to primary participants include labour market earnings, avoided costs of grade repetition and special education in primary and secondary school, health care, and crime. The last component, which is not included in this evaluation, amounts to $8 \%$ of the estimated benefits from changes to primary participants. The benefit-cost ratio from changes to primary participants is 9.59 , which can be compared to 6.31-38.97 in this evaluation (for the small population, excluding the self-help book).

\section{Implications for Policy and Practice}

The evaluated parenting programs are available and used at different rates in Sweden, where the most frequently used is Comet, followed by COPE. In a survey conducted by the National Public Health Institute of Sweden (2013) it was reported that just about a third of the 290 municipalities in Sweden had COPE on offer to parents. None of them currently offers the self-help book as a preventive measure. The results from this study are therefore highly applicable to local decision-making. Firstly, from a clinical perspective, parenting programs may be implemented through a stepped care approach. The self-help book is inexpensive, yields high returns and is effective at reducing behavioural problems even if only few parents are reached. It requires no training nor execution by practitioners, thus solely entails a cost of the book itself. However, it does not generate the same effects as COPE or the Incredible Years, thereby producing smaller net present values. To augment the health benefits and if more resources are available, care may be expanded by offering these programs. However, further research is needed to investigate its implementation through stepped-care.

Concerning applicability of results to local authority decision-making, we estimated the interventions' impact if implemented in different population sizes. As a majority of local authorities within the Swedish context are below 15,000 inhabitants, which may be the case also in other countries, it may be difficult to finance preventive strategies due to budget constraints. This is true especially if other sectors may reap the health and financial benefits of these investments. We put forth evidence in this study that even the small populations will secure benefits, also if only including their own potential cost-offsets, as was done in the sixth sensitivity analysis. Hence, regardless of the size of the implementing authority, most of the evaluated parenting interventions yield positive returns throughout.

In terms of generalizability of the results, it may well apply to local authorities, regional offices or other instances 
that are delivering parenting interventions in other countries, who have a similar financing and service provision system to Sweden. As such have shown to be as effective outside as within their country of origin (Gardner et al. 2016), it boils down to whether our economic analysis including implementation costs and price levels, in relation to health care, educational support and projected lifetime earnings, is similar in other settings. Even though the results ought to be interpreted with caution outside of Sweden, they may well be applicable to countries with publicly funded health care and educational sectors and with service delivery of parenting programs on a local level.

\section{Strengths and Limitations}

To the authors' knowledge, this is the first study looking at the longer-term economic consequences for parenting interventions delivered in different sized local authorities. The current study makes use of univariate probabilistic and sensitivity analyses to account for parameter uncertainty and various assumptions made within the model. This offers strength to the results, both statistically and clinically by controlling for data variations and "real life" factors that might affect the results. In addition, the Markov modelling technique has an advantage as it incorporates yearly changes in the disease burden and uses epidemiology to map related costs, in comparison to other longer-term health economic studies within the same topic. We have attempted to make conservative assumptions throughout the analysis and ensuring transparency by aiming to point out and discuss assumptions made as well as referencing the technical report related to the model used.

However, a few challenges may be noted, in addition to the limitations explained in the initial trial and discussed at large in the effectiveness paper (Stattin et al. 2015). Firstly, we include both the post-test and follow-up effectiveness results in the base case analysis, but data was only available for the control group at post-test due to ethical considerations. We used the data from the control group at post-test to inform the follow-up measure, which means using the same "natural remission" at follow-up as at post-test. Data on natural remittance levels (remittance from ADHD, CD and $\mathrm{ADHD} / \mathrm{CD}$ without any intervention) from the literature show lower rates than found in this study (Lahey et al. 2005; Biedermanet al. 2006a).

On a similar note, we have assumed that the modelled problems (ADHP, CP and co-existing ADHP/CP) follow a similar epidemiological trend as the disorders, which may have affected the results in an unknown direction. We also used SNAP-IV as a clinical cut-off level for ADHP, which has only been validated for children up to the age of 11 , and the oldest in our sample are 12-year-olds.

Another issue is the health states modelled in combination with related costs. It is unlikely that scoring below a certain cut-off after an intervention would effectively remove the burden of the problems to such an extent that services used would diminish directly and completely. The assumption that we would directly see cost-offsets due to an individual remitting from one of the "problem" states should therefore be taken into consideration when interpreting the results. Also, since no cost-data was collected alongside the trial, we had to estimate this from the literature which generated average costs. Future studies ought to use validated instruments for data collection on costs to be able to conduct a full economic evaluation with individual-level costs. In addition, productivity losses were estimated in the model, however, behaviour problems are associated with a range of consequences in adulthood, whose costs have not been accounted for in the estimation of longer-term cost-offsets. This is likely to underestimate the magnitude of offsets.

Lastly, it is important to note that no sub-group analyses have been conducted and that no other effects other than those on the children have been included in these analyses. We therefore do not know for which children these interventions work; it seems plausible that compliance rates of the self-help book or other barriers to the effectiveness of parenting interventions may be affected by demographic variables, such as language/cultural background or parental well-being (Gardner et al. 2010; Ozbek et al. 2018). Initial level or amount of problems may also impact the results. If only some groups of parents experience positive effects of parenting interventions, it may contribute to inequity in both who is targeted by public services, as well as who they effectively work for. In addition, the larger societal effects of these interventions, as on parents own health and the wellbeing of the people in close contact with the children are not considered. Such indirect costs are likely to be affected, and we assume our cost estimates to be underestimated due to this exclusion. Therefore, it is of relevance for future studies to collect more extensive data to be able to conduct subgroup analyses to understand who benefits from these types of interventions. The economic evidence may be expanded further by including the effect of parenting interventions on individuals other than the children themselves.

\section{Conclusion}

Economic models for early investments in child mental health may generate evidence that is useful for local level decision makers. By using such a model for parenting interventions, we have been able to establish their long-term societal costs and potential returns. All the evaluated interventions within this study appear to be of good value-formoney and yield substantial societal returns when adapted 
to various community populations, evidence that is relevant for local decision-making.

Acknowledgements Open access funding provided by Uppsala University.

Funding This study was funded by The Swedish Research Council (2014-10,128).

\section{Compliance with Ethical Standards}

Conflict of interest All authors declare that they have no conflict of interest.

Ethical Approval This article does not contain any studies with human participants or animals performed by any of the authors.

Open Access This article is distributed under the terms of the Creative Commons Attribution 4.0 International License (http://creativeco mmons.org/licenses/by/4.0/), which permits unrestricted use, distribution, and reproduction in any medium, provided you give appropriate credit to the original author(s) and the source, provide a link to the Creative Commons license, and indicate if changes were made.

\section{References}

Abrahamse, L. L. E. (2015). Treating young children's disruptive behavior problems. Amsterdam: University of Amsterdam.

American Psychiatric Association. (2013). Diagnostic and statistical manual of mental disorders (5th ed.). Washington, DC: American Psychiatric Association.

Aos, S., Lieb, R., Mayfield, J., Miller, M., \& Pennucci, A. (2004). Benefits and costs of prevention and early intervention programs for youth. Olympia: Washington State Institute for Public Policy.

Barnett, W. S., \& Masse, L. N. (2007). Comparative benefit-cost analysis of the Abecedarian program and its policy implications. Economics of Education Review, 26(1), 113-125. https://doi. org/10.1016/j.econedurev.2005.10.007.

Bevilacqua, L., Hale, D., Barker, E. D., Viner, R., \& Adolescence-limited, A. L. (2017). Conduct problems trajectories and psychosocial outcomes: A systematic review and meta-analysis. European Child and Adolescent Psychiatry. https://doi.org/10.1007/s0078 7-017-1053-4.

Biederman, J., Monuteaux, M. C., Mick, E., Spencer, T., Wilens, T. E., Klein, K. L., et al. (2006a). Psychopathology in females with attention-deficit/hyperactivity disorder: A controlled, five-year prospective study. Biological Psychiatry, 60(10), 1098-1105. https://doi.org/10.1016/j.biopsych.2006.02.031.

Biederman, J., Monuteaux, M. C., Mick, E., Spencer, T., Wilens, T. E., Silva, J. M., et al. (2006b). Young adult outcome of attention deficit hyperactivity disorder: A controlled 10-year follow-up study. Psychological Medicine, 36(2), 167-179. https://doi.org/10.1017/ S0033291705006410.

Björklund, A., Fredriksson, P., Gustafsson, J.-E., \& Öckert, B. (2010). Labour market effects of the swedish educational policy: What is the evidence from research? (Den Svenska Utbildningspolitikens Arbetsmarknadseffekter: Vad Säger Forskningen?). Uppsala: Institutet för arbetsmarknadspolitisk utvärdering (IFAU).

Bonin, E. M., Stevens, M., Beecham, J., Byford, S., \& Parsonage, M. (2011). Costs and longer-term savings of parenting programmes for the prevention of persistent conduct disorder: A modelling study. BMC Public Health, 11(1), 803. https://doi. org/10.1186/1471-2458-11-803.

Braun, S., Zeidler, J., Linder, R., Engel, S., Verheyen, F., \& Greiner, W. (2013). Treatment costs of attention deficit hyperactivity disorder in Germany. European Journal of Health Economics, 14(6), 939-945. https://doi.org/10.1007/s10198-012-0440-5.

Briggs, A. H., Weinstein, M. C., Fenwick, E. A. L., Karnon, J., Sculpher, M. J., \& David Paltiel, A. (2012). Model parameter estimation and uncertainty: A report of the ISPOR-SMDM Modeling good research practices task force- 6 on behalf of the ISPORSMDM modeling good research practices task force background to the task force. Value in Health, 15(15), 835-842. https://doi. org/10.1016/j.jval.2012.04.014.

Bussing, R., Fernandez, M., Harwood, M., Wei Hou, W., Garvan, C. W., Eyberg, S. M., et al. (2008). Parent and teacher SNAPIV ratings of attention deficit/hyperactivity disorder symptoms: Psychometric properties and normative rating from a school district sample. Assessment, 15(3), 317-328. https://doi. org/10.1177/1073191107313888.Parent.

Colvin, A., Eyberg, S., \& Adams, C. (1999). Restandardization of the eyberg child behavior inventory.

Cunha, B. F., \& Heckman, J. (2007). The technology of skill formation. American Economic Review, 97(2), 31-47.

Cunningham, C. E., Bremner, R., \& Boyle, M. (1995). Large group community-based parenting programs for families of preschoolers at risk for disruptive behaviour disorders: Utilization, cost effectiveness, and outcome. Journal of Child Psychology and Psychiatry and Allied Disciplines, 36(7), 1141-1159.

Erskine, H. E., Ferrari, A. J., Polanczyk, G. V., Moffitt, T. E., Murray, C. J. L., Vos, T., et al. (2014). The global burden of conduct disorder and attention-deficit/hyperactivity disorder in 2010. Journal of Child Psychology and Psychiatry and Allied Disciplines, 55(4), 328-336. https://doi.org/10.1111/jcpp.12186.

Erskine, H. E., Moffitt, T. E., Copeland, W. E., Costello, E. J., Ferrari, A. J., Degenhardt, L., et al. (2015). A heavy burden on young minds: The global burden of mental and substance use disorders in children and youth. Psychological Medicine, 45(7), 1551-1563. https://doi.org/10.1017/S0033291714002888.A.

Erskine, H. E., Norman, R. E., Ferrari, A. J., Chan, G. C. K., Copeland, W. E., Whiteford, H. A., et al. (2016). Long-term outcomes of attention-deficit/hyperactivity disorder and conduct disorder: A systematic review and meta-analysis. Journal of the American Academy of Child and Adolescent Psychiatry, 55(10), 841-850. https://doi.org/10.1016/j.jaac.2016.06.016.

Fletcher, J. M. (2014). The effects of childhood ADHD on adult labor market outcomes. Health Economics, 23, 159-181.

Folkhälsomyndigheten. (2014). Skolbarns hälsovanor i Sverige 2013/14. Stockholm, Sweden

Forster, M. (2009). Five times more love (Fem gånger mer kärlek). Stockholm: Natur\&Kultur.

Furlong, M., McGilloway, S., Bywater, T., Hutchings, J., Smith, S. M., \& Donnelly, M. (2013). Cochrane review: Behavioural and cognitive-behavioural group-based parenting programmes for early-onset conduct problems in children aged 3 to 12 years (Review). Evidence-Based Child Health: A Cochrane Review Journal, 8(2), 318-692. https://doi.org/10.1002/ebch.1905.

Gardner, F., Hutchings, J., Bywater, T., \& Whitaker, C. (2010). Who Benefits and how does it work? Moderators and mediators of outcome in an effectiveness trial of a parenting intervention. Journal of Clinical Child \& Adolescent Psychology, 39(4), 568-580.

Gardner, F., Montgomery, P., \& Knerr, W. (2016). Transporting evidence-based parenting programs for child problem behavior (age 3-10) between countries: Systematic review and metaanalysis. Journal of Clinical Child and Adolescent Psychology, 
45(6), 749-762. https://doi.org/10.1080/15374416.2015.10151 34.

Global Burden of Disease (GBD) 2016 Disease and Injury Incidence and Prevalence Collaborators*. (2017). Global, regional, and national incidence, prevalence, and years lived with disability for 328 acute and chronic diseases and injuries in 195 countries, 1990-2016: A systematic analysis for the Global Burden of Disease Study 2016. The Lancet, 390, 1211-1259.

Hakkaart-van Roijen, L., Zwirs, B. W. C., Bouwmans, C., Tan, S. S., Schulpen, T. W. J., Vlasveld, L., et al. (2007). Societal costs and quality of life of children suffering from attention deficient hyperactivity disorder (ADHD). European Child and Adolescent Psychiatry, 16(5), 316-326. https://doi.org/10.1007/s0078 7-007-0603-6.

Heckman, J., Humphries, J. E., \& Veramendi, G. (2016). Returns to education: The causal effects of education on earnings. Health and Smoking. https://doi.org/10.3386/w22291.

Heckman, J. J., Moon, S. H., Pinto, R., Savelyev, P. A., \& Yavitz, A. (2009). The rate of return to the high/scope perry preschool program (No. 15471). Retrieved from http://www.nber.org/papers/ w15471

Högström, J., Olofsson, V., Özdemir, M., Enebrink, P., \& Stattin, H. (2017). Two-year findings from a national effectiveness trial: Effectiveness of behavioral and non-behavioral parenting programs. Journal of Abnormal Child Psychology, 45(3), 527-542. https://doi.org/10.1007/s10802-016-0178-0.

Holden, S. E., Jenkins-jones, S., Poole, C. D., Morgan, C. L., Coghill, D., \& Currie, C. J. (2013). The prevalence and incidence, resource use and financial costs of treating people with attention deficit/ hyperactivity disorder (ADHD) in the United Kingdom (1998 to 2010). Child and Adolescent Psychiatry and Mental Health, 7(34), 1-13.

Hultkrantz, L., Karpaty, P., \& Vimefall, E. (2017). Education-earnings linkage for assessing societal benefits of interventions for children and youth in Sweden. Psychosocial Intervention, 26(3), 171-179. https://doi.org/10.1016/j.psi.2017.06.001.

Jacobson, N. S., \& Truax, P. (1991). Clinical significance: A statistical approach to defining meaningful change in psychotherapy research. Methodological Issues \& Strategies in Clinical Research, 59(1), 631-648.

Kattan, M. W. (2009). Encyclopedia of medical decision making (1st ed.). Thousand Oaks: SAGE Publications Inc.

Kessler, R. C., Amminger, G. P., Aguilar-Gaxiola, S., Alonso, J., Lee, S., \& Üstün, T. B. (2007). Age of onset of mental disorders: A review of recent literature. Current Opinion in Psychiatry, 20(4), 359-364. https://doi.org/10.1097/YCO.0b013e32816ebc8c.

Kim-cohen, J., Arseneault, L., Caspi, A., Tomás, M. P., Sc, B., Moffitt, T. E., et al. (2005). Children: A longitudinal epidemiological study. Psychiatry Interpersonal and Biological Processes, 162, 1108-1117. https://doi.org/10.1176/appi.ajp.162.6.1108.

Kling, A., \& Forster, M. (2010). A randomized controlled effectiveness trial of parent management training with varying degrees of therapist support. Behavior Therapy, 41(4), 530-542. https://doi. org/10.1016/j.beth.2010.02.004.

Klora, M., Zeidler, J., Linder, R., Verheyen, F., \& von der Schulenburg, J. M. G. (2015). Costs and treatment patterns of incident ADHD patients-A comparative analysis before and after the initial diagnosis. Health Economics Review, 5(1), 1-9. https:// doi.org/10.1186/s13561-015-0078-y.

Knapp, M., King, D., Healey, A., \& Thomas, C. (2011). Economic outcomes in adulthood and their associations with antisocial conduct, attention deficit and anxiety problems in childhood. Journal of Mental Health Policy and Economics, 14(3), 137-147.

Lahey, B. B., Loeber, R., Burke, J. D., \& Applegate, B. (2005). Predicting future antisocial personality disorder in males from a clinical assessment in childhood. Journal of
Consulting and Clinical Psychology, 73(3), 389-399. https://doi. org/10.1037/0022-006X.73.3.389.

Le, H. H., Hodgkins, P., Postma, M. J., Kahle, J., Sikirica, V., Setyawan, J., et al. (2014). Economic impact of childhood/adolescent ADHD in a European setting: The Netherlands as a reference case. European Child and Adolescent Psychiatry, 23(7), 587-598. https:// doi.org/10.1007/s00787-013-0477-8.

Litschge, C. M., Vaughn, M. G., \& McCrea, C. (2010). The empirical status of treatments for children and youth with conduct problems an overview of meta-analytic studies. Research on Social Work Practice, 20, 21-35.

Little, M., \& Edovald, T. (2012). Return on investment. The evaluation of costs and benefits of evidence-based programs. Psychosocial Intervention, 21(2), 215-221. https://doi.org/10.5093/in2012a13.

Mannuzza, S., Klein, R. G., Bessler, A., Malloy, P., \& Lapadula, M. (1998). Adult psychiatric status of hyperactive boys grown up. American Journal of Psychiatry, 155(4), 493-498. https://doi. org/10.1176/ajp.155.4.493.

Mihalopoulos, C., Sanders, M. R., Turner, K. M. T., Murphy-brennan, M., \& Carter, R. (2007). Does the triple P positive parenting program provide value for money? Australian and New Zealand Journal of Psychiatry, 41, 239-246.

Moretti, M. M., Braber, K., \& Obsuth, I. (2013). Connect: An Attachment-focused treatment group for parents and caregivers-A principle based manual. Burnaby: Simon Fraser University.

Morgenstern, H., \& Bursic, E. S. (1982). A method for using epidemiologic data to estimate the potential impact of an intervention on the health status of a target population. Journal of Community Health, 7(4), 292-309. https://doi.org/10.1007/BF01318961.

Norén Selinus, E., Molero, Y., Lichtenstein, P., Anckarsäter, H., Lundström, S., Bottai, M., et al. (2016). Subthreshold and threshold attention deficit hyperactivity disorder symptoms in childhood: Psychosocial outcomes in adolescence in boys and girls. Acta Psychiatrica Scandinavica, 134(6), 533-545. https://doi.org/10.1111/ acps. 12655 .

Nystrand, C. (2018). Technical report: Markov model used to model parenting interventions for the prevention of externalizing behavior problems in children and adolescents.

O’Brien, M., \& Daley, D. (2011). Self-help parenting interventions for childhood behaviour disorders: A review of the evidence. Child: Care, Health and Development, 37(5), 623-637. https://doi.org/ 10.1111/j.1365-2214.2011.01231.x.

O’Neill, D., McGilloway, S., Donnelly, M., Bywater, T., \& Kelly, P. (2013). A cost-effectiveness analysis of the Incredible Years parenting programme in reducing childhood health inequalities. European Journal of Health Economics, 14(1), 85-94. https://doi. org/10.1007/s10198-011-0342-y.

Oh, E., \& Bayer, J. K. (2015). Parents' help-seeking processes for early childhood mental health problems. Child and Adolescent Mental Health, 20(3), 149-154. https://doi.org/10.1111/camh.12081.

Ozbek, A., Gencer, O., \& Mustan, A. T. (2018). Which parents dropout from an evidence-based parenting programme (Triple-P) at CAMHS? Comparison of programme-completing and dropout parents. Clinical Child Psychology and Psychiatry. https://doi. org/10.1177/1359104518792294.

Pavuluri, M. N., Luk, S.-L., \& McGee, R. (1996). Help-seeking for behavior problems by parents of preschool children: A community study. Journal of the American Academy of Child and Adolescent Psychiatry, 35(2), 215-222. https://doi.org/10.1097/00004583199602000-00015.

Reynolds, A. J., Temple, J. A., White, B. A., Ou, S.-R., \& Robertson, D. L. (2011). Age-26 cost-benefit analysis of the child-parent center early education program. Child Development. https://doi. org/10.1111/j.1467-8624.2010.01563.x.Age-26.

Romeo, R., Knapp, M., \& Scott, S. (2006). Economic cost of severe antisocial behaviour in children-and who pays it. The British 
Journal of Psychiatry, 188, 547-553. https://doi.org/10.1192/ bjp.bp.104.007625.

Sampaio, F., Barendregt, J. J., Feldman, I., Lee, Y. Y., Sawyer, M. G., Dadds, M. R., et al. (2018). Population cost-effectiveness of the Triple $\mathrm{P}$ parenting programme for the treatment of conduct disorder: An economic modelling study. European Child and Adolescent Psychiatry, 27(7), 933-944. https://doi.org/10.1007/ s00787-017-1100-1.

Sampaio, F., Enebrink, P., Mihalopoulos, C., \& Feldman, I. (2016). Cost-effectiveness of four parenting programs and bibliotherapy for parents of children with conduct problems. Journal of Mental Health Policy and Economics, 19(4), 201-212.

Sanders, M. R. (1999). Triple P-positive parenting program: Towards an empirically validated multilevel parenting and family support strategy for the prevention of behavior and emotional problems in children. Clinical Child and Family Psychology Review, 2(2), 71-90. https://doi.org/10.1023/A:1021843613840.

Scott, S., Knapp, M., Henderson, J., \& Maughan, B. (2001). Financial cost of social exclusion: Follow up study of antisocial children into adulthood. British Medical Journal, 323(7306), 191-191. https://doi.org/10.1136/bmj.323.7306.191.

Snell, T., Knapp, M., Healey, A., Guglani, S., Evans-Lacko, S., Fernandez, J. L., et al. (2013). Economic impact of childhood psychiatric disorder on public sector services in Britain: Estimates from national survey data. Journal of Child Psychology and Psychiatry and Allied Disciplines, 54(9), 977-985. https://doi.org/10.1111/ jcpp. 12055.

Statistics Sweden (SCB). (2016). Longitudinal integration database for health insurance and labour market studies (LISA). Retrieved from http://www.scb.se/en/services/guidance-for-researcher s-and-universities/vilka-mikrodata-finns/longitudinella-register/ longitudinal-integration-database-for-health-insurance-and-labou r-market-studies-lisa/

Stattin, H., Enebrink, P., Özdemir, M., \& Giannotta, F. (2015). A national evaluation of parenting programs in Sweden: The shortterm effects using an RCT effectiveness design. Journal of Consulting and Clinical Psychology, 83(6), 1069-1084. https://doi. org/10.1037/a0039328.

Swanson, J. M. (1992). The SNAP-IV Teacher and Parent Rating Scale. Retrieved 23 November, 2017, from https://www.crfht.ca/files /8913/7597/8069/SNAPIV_000.pdf

Sweden Statistics (Statistiska Centralbyrån). (2018). Population by region, marital status, age and sex. Year 1968-2017 (Folkmängden efter region, civilstånd, ålder och kön. År 1968-2017). Retrieved 3 April, 2018, from http://www.statistikdatabasen.scb. se/pxweb/en/ssd/START_BE_BE0101_BE0101A/Befolkning Ny/?rxid=f254b1d1-f1f7-4407-871d-f9d4d8d5da71

Swedish Association of Local Authorities and Regions. (2017). Classification of Swedish municipalities 2017, 1 (November 2016), 1.

Swedish National Agency for Education (Skolverket). (2017). National Statistics. Retrieved from https://www.skolverket.se/skolutveck ling/statistik/sok-statistik-om-forskola-skola-och-vuxenutbildning
Telford, C., Green, C., Logan, S., Langley, K., Thapar, A., \& Ford, T. (2013). Estimating the costs of ongoing care for adolescents with attention-deficit hyperactivity disorder. Social Psychiatry and Psychiatric Epidemiology, 48(2), 337-344. https://doi.org/10.1007/ s00127-012-0530-9.

The Campbell and Cochrane Economics Methods Group. (n.d.). CCEMG - EPPI-Centre Cost Converter. Retrieved 20 May, 2018, from http://eppi.ioe.ac.uk/costconversion/default.aspx

The Danish National Center for Social Research (Viden til Velfard, V. (2018). Socio-economic investment model (Socialekonomisk investeringsmodel (SOM)). Retrieved 1 December, 2017, from http://www.kora.dk/udgivelser/udgivelse/i15582/Socialoekonomis k-investeringsmodel-(SØM)---Dokumentation

The National Public Health Institute of Sweden. (2013). Current practice and work with parenting interventions in municipalities, counties, regional offices and the voluntary sector (Så arbetar kommuner, landsting, kommun- och regionförbund och ideella organisationer med föräldrastöd). Sweden: Stockholm.

Thernlund, G., \& Schacht, A. (2010). Atomoxetine's effect on societal costs in Sweden. Journal of Attention Disorders, 13(6), 618-628. https://doi.org/10.1177/1087054709332163.

Thomas, R., \& Zimmer-Gembeck, M. J. (2007). Behavioral outcomes of parent-child interaction therapy and triple $\mathrm{P}$-Positive parenting program: A review and meta-analysis. Journal of Abnormal Child Psychology, 35, 475-495. https://doi.org/10.1007/s1080 2-007-9104-9.

Vos, T., Barber, R. M., Bell, B., Bertozzi-Villa, A., Biryukov, S., Bolliger, I., et al. (2015). Global, regional, and national incidence, prevalence, and years lived with disability for 301 acute and chronic diseases and injuries in 188 countries, 1990-2013: A systematic analysis for the Global Burden of Disease Study 2013. The Lancet, 386(9995), 743-800. https://doi.org/10.1016/S0140 -6736(15)60692-4.

Washington State Institute for Public Policy. (2018). Behavioral parent training $(B P T)$ for children with $A D H D$. Washington, United States. Retrieved from https://www.wsipp.wa.gov/BenefitCost/ Program $/ 88$

Webster-Stratton, \& Hammond, M. (1998). Conduct problems and level of social competence in Head Start children: prevalence, pervasiveness, and associated risk factors. Clinical Child and Family Psychology Review, 1(2), 101-124.

Webster-Stratton, C., Reid, M. J., Hammond, M., Reid, M. J., Treating, M. H., Webster-stratton, C., et al. (2004). Treating children with early-onset conduct problems: intervention outcomes for parent, child, and teacher training. Journal of Clinical Child and Adolescent Psychology, 33(1), 105-124. https://doi.org/10.1207/S1537 4424JCCP3301.

Publisher's Note Springer Nature remains neutral with regard to jurisdictional claims in published maps and institutional affiliations. 